\title{
Board 129: Girl Scout Engineering Programs' Impact on Middle School Girls' Engineering Identities
}

\section{Abigail Clark, Ohio State University}

Abigail Clark is currently a Ph.D. student in the Department of Engineering Education at The Ohio State University. She is currently advised by Dr. Rachel Kajfez, and is part of the RIME collaborative (https://u.osu.edu/rimetime). Her research interests include engineering identity development in K12 students, engineering education in informal settings, and women's experiences in the engineering field. Prior to coming to Ohio State, Abigail worked as a researcher at Battelle Memorial Institute in Columbus, $\mathrm{OH}$. She holds a bachelor's degree in mechanical engineering from Ohio Northern University. 


\section{Methods for Assessing the Impact of Girl Scout Engineering Programs on Middle School Girls' Engineering Identities}

Abigail Clark, PhD Student

Advised by Dr. Rachel Kajfez

\section{INTRODUCTION}

Despite decades of attempts to improve the gender parity in the engineering field, women remain underrepresented in the field of engineering, with about $20 \%$ of engineering degrees being awarded to women, which has remained essentially unchanged for 15 years [1]. In order to rectify this situation, girls must be made aware of and given the opportunity to develop interests in engineering long before they choose a career path.

Engineering has become a growing part of the $\mathrm{K} 12$ classroom and a focus outside of the classroom as well. Television shows, toys, and games are designed to introduce children to engineering and many organizations have developed or reinvigorated STEM programs. The Girl Scouts recently announced a new focus in STEM, including engineering programming at every age level. Nearly 2 million girls are Girl Scout members [2] so Girl Scouts may be a way to introduce many girls to engineering who may not have been otherwise exposed to the engineering field.

\section{RESEARCH QUESTION}

How does the completion of an engineering badge or Journey impact middle school girls engineering identity?

\section{THEORETICAL FRAMEWORK}

Identity will be examined through the framework of Possible Future Selves [3]. Because middle school girls are not yet engineers, identity will be operationalized as how girls view themselves as potential future engineers. Identity development is important to understand as an engineering identity is tied to recruitment and retention [4]

\section{METHODS}

This study will be approached qualitatively, with data being collected through interviews with Girl Scouts working on engineering badge or Journey and observations as they work on the engineering programming throughout the process.

\section{Participants}

Through a partnership with a local Girl Scout Council, middle school Girl Scout troops who are planning to work on engineering badges will be recruited. Middle school was chosen due to the importance of this time for students who are planning a STEM career in middle school are more likely to graduate with an engineering or science degree [5]

\section{Data Collection and Analysis}

Data will be collected through interviews and observations of Girl Scouts working on engineering badges and Journeys. The interview protocol and observation protocol will be piloted and adjustments will be made as necessary. The interviews will be analyzed by iterative coding and theme generation, and will be triangulated using the observations.

\section{NEXT STEPS}

The results of this study will provide insight on how engineering identity develops in middle school girls. Understanding this development will help design programs to actively support identity development and help improve gender representation in the engineering field.

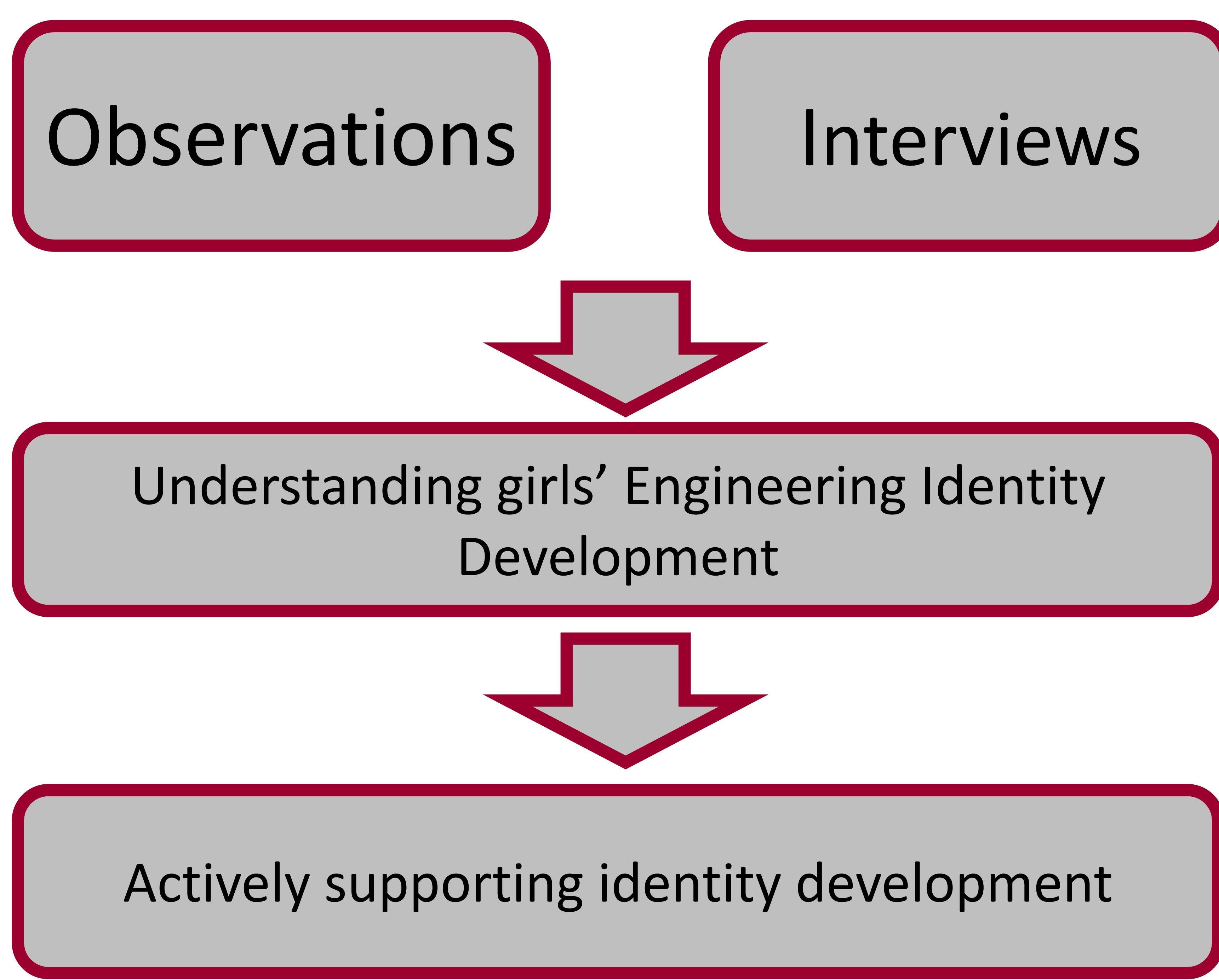

References

[1] National Science Board. (2018). Science \& Engineering Indicators. Washington

[2]GSUSA. (2015). Annual Report. Retrieved from

\section{https://www girlscouts org/content/dam/girlscouts-gsusa/forms-and}

documents/about-gir-scouts/facts/GSUSA Annual Repert 2015 pdf

3] Markus, H. R., \& Nurius, P. (1986). Possible Selves. American Psychologist, 41(9) , 954-969.

[4] Beam, T., Pierrakos, O., Constantz, J., Johri, A., \& Anderson, R. (2009). Preliminary Findings on Freshmen Engineering Students' Professional Identity : Implications for Recruitment and Reten. In American Society for Engineering Education. [5] Tai, R. H., Liu, C. Q., Maltese, A. V, \& Fan, X. (2006). CAREER CHOICE: Enhanced: Planning Early for Careers in Science. Science, 312(5777), 1143-1144. https://doi.org/10.1126/science.1128690 